DOI: 10.2478/ausfm-2021-0011

\title{
The Role of Experimenting with the Human Voice in Film Music in the Representation of the Human/Alien Divide: the Case of Arrival (2016)
}

\author{
Nicolás Medina and Miklós Kiss \\ University of Groningen (The Netherlands) \\ E-mails: m.kiss@rug.nl,n.medina.maranon@rug.nl
}

\begin{abstract}
This article focuses on the musical dimension of experimentation in the creative space of science fiction film, concerning its uncanny, new and fantastic places, and otherworldly encounters within fictional, but possible worlds. The aim is to consider the function and potential of the audible - to examine how sound is used in the filmic exploration of the boundaries between the human and the alien (the unknown). More particularly, we are interested in the role that human voice-like and human vocal sounds can play in this divide, as we believe manipulations with such audible qualities contribute greatly to the emotional dimension of cinematic stories of otherworldly encounters. For that purpose, we concentrate on Denis Villeneuve's Arrival (2016) and its soundtrack composed by Jóhann Jóhannsson, who resorts to different singing practices and vocal techniques to accompany a story charting the territories between the human and the alien.
\end{abstract}

Keywords: voice, soundtrack, human/alien divide, Arrival, Jóhann Jóhannsson.

\section{Introduction}

Science fiction seems to be the ideal generic context to raise all sorts of existential “what if...?" questions, hypothesize about possible dystopian and utopian futures, and ultimately reflect upon the very essence of human nature. Cara Marisa Deleon emphasizes the relevance of unfamiliarity as one of the key elements of the genre (Deleon 2010,13). This article focuses on the musical dimension of how cinema addresses unfamiliarity within the science fiction genre's uncanny, new and fantastic places, and otherworldly encounters. The aim is to consider the function and potential of the audible - to examine how sound is used in the filmic exploration of the boundaries between the human and the alien (the 
unknown). More particularly, we are interested in the role that voice-like and vocal sounds play in exploring this divide.

The voice, as the "faculty whereby human beings (and some other creatures) produce sound (speech, music and other sounds) through use of the lungs, throat and mouth as an acoustic system" (Shepherd et al. 2003, 455), is the most organic instrument at our disposal, and therefore often comes to signify humanness. We believe that experimentation with the human voice (or voice resembling instruments) offers a series of productive affordances, which can contribute greatly to the emotional dimension of cinematic stories of otherworldly encounters especially if we consider how many science fiction films seem to be looking to the unknown in order to reflect about our human selves. Recently, a few film sound designers and directors have been exploring this potential of the human voice using its spectral features, exploring different vocal practices such as overtone singing, looping/splicing/processing - to humanize sounds marked as alien. Foregrounding the organic/non-organic binary, this artistic work is an important part of a broader effort to create empathy and identification across difference and reduce the Otherness of the various Others, like the animal or the alien.

Our case study is Denis Villeneuve's science fiction film Arrival (2016) and its experimental musical soundtrack using human vocal and voice-like sounds throughout the score. Composer Jóhann Jóhannsson employs different singing practices and vocal approaches to create the musical atmosphere of the film, making use of the varied affordances that vocal sounds might represent in this story about communication with alien species and among humans. The blending of natural and processed voices, the instances of overtone singing, or the sampling/looping of existing vocal recordings are techniques to create sounds which, although familiar to contexts such as avant-garde music, are rarely present in mainstream cinema. Our aim is to relate the soundtrack's experimentation with human voices to the film's unfolding notions of spiritualism, unpacking its contribution to the fiction's understanding of the nonhuman as well as to a fantastic extension of our knowledge on humanness.

\section{Scoring with Voices in Arrival}

Written by Eric Heisserer (based on the short novel by Ted Chiang), Arrival presents the story of linguist Louise Banks (Amy Adams) during the visit of twelve extraterrestrial spacecrafts in various locations on Earth. The US Army brings Banks and physicist Ian Donnelly (Jeremy Renner) to their encampment in Montana, 
where a whole team of experts struggles to decipher the aliens' intentions, amid threats of global panic and crisis. As the story unfolds, the heptapods (a moniker coined by the scientists after the aliens' seven feet) ultimately succeed in communicating their purpose: teaching humanity their special language, which entails the broadening of the perception of reality by changing humans' linear perception of time. The movie reflects on the power of communication and language, both on an extra-terrestrial and human level, and it is precisely because of this core interest in charting the territories between the human and the alien that we deem it a stimulating case (of film music) to explore in depth.

Sharon O’Connell points out how Icelandic composer Jóhann Jóhannsson tends to treat his film scores as a constitutive element of the overall sound design, that is, not as an independent composition imposed on it (O'Connell 2016). ${ }^{1}$ This practice of sonic distribution in the soundtrack is what Rick Altman, together with McGraw Jones and Sonia Tatroe, called the mise-en-bande, as an equivalent of mise-en-scène (Altman et al. 2000, 341). The mise-en-bande is constructed in such a way that, at times, there seems to be no clear distinction between the constituents of the sonic cinematic space. Deleon explains this through the early example of Fred M. Wilcox's Forbidden Planet (1956), in which "it is almost unclear as to where the score ends and the sound design begins; the same tones found in the score are present within the sound effects of the diegetic world" (Deleon 2010, 16). Jóhannsson uses a similar scoring approach in Arrival, resulting in enriched sonic spaces and, thus, a more vibrant diegetic universe.

Remarkably, the sound design team approached the project of constructing the sonic spaces of the otherworldly encounters resorting exclusively to natural sources of sounds. Sylvain Bellemare, supervising sound designer for Arrival, explains their decision to leave out any electronic sounds when creating the aural environments, opting for "something completely natural sounding, organic sounding," including wind recordings (with different levels of processing) as well as rocks, earthquake or ice crackling (Clark and Stanze 2016a). Similarly, in charge of the heptapod vocals design, Dave Whitehead and Michelle Child worked with natural elements and sounds. They sampled from kokako and tui birdsongs, modified the pitch of camels' gurgling sounds, they were breathing through bagpipes or Māori instruments like the pūtōrino or the didjeridu to get different noises, even created a lung out of rice paper filled with water to simulate breathing (Clark and Stanze 2016a).

1 Other films featuring compositions by Jóhannsson are Prisoners (Villeneuve, 2013), Sicario (Villeneuve, 2015) or Mandy (Panos Cosmatos, 2018), to name but a few titles that could also support such an observation. 
Let's highlight and briefly describe some of the key moments in which natural voices and voice-like sounds appear in Arrival's score, serving an important role in building the film's sonic spaces.

First, it should be noted that both Arrival's opening and epilogue sequences, borrowing minimalist English composer Max Richter's On the Nature of Daylight, differ in their use of music compared to the rest of the film. In an interview (Hall 2016), Jóhannsson recalls how Richter's piece was used early on during the editing process, and how director Villeneuve's decision to keep it resulted in a big contrast in tone with the rest of the film. ${ }^{2}$ In this way, Arrival seems to invert the schema of "readability" discussed by Deleon, who argues that classical orchestration eases the readability of the narrative within a genre that is already strange, providing "a level of comfort and a solid foundation, which is firmly established and its meaning known to the viewer" (Deleon 2010, 14). Deleon refers to Tim Burton's Mars Attacks! (1996) and the film's score written by Danny Elfman as an example, where the opening sequence "states that yes, this is a science fiction film, however, after the credits end, the score reverts to recognizable instruments and orchestrations" (Deleon 2010, 15). On the contrary, in Arrival, while Richter's opening and ending segments channel unambiguous emotions, the bulk of the film features less straightforward musical experimentations.

The film's initial steps towards such experimentations, the moment when voice-like sounds feature in the soundtrack for the first time, is when Louise Banks decides to take part in the investigation and is flown to the basecamp (Jóhannsson: Arrival at 00:17:34 in the film). Once her helicopter approaches the site, a series of shots and counter-shots place us in Banks's internally ocularized and auricularized point of view, trying to locate the spacecraft. The soundtrack is first occupied only by the helicopter's blades; this sound is slowly shifted to the background of the sonic space, leaving room for a deep and gradually increasing atmospheric sound created by a piano drone (analogue tape loop) - an auditory transition that contributes to the viewer's growing thrill. Finally, she (together with the viewer) gets a sight of the spacecraft. A couple of seconds after the alien ship completely fills the screen in an extreme wide shot, a series of single notes, sang as wailing-like sounds, are heard, gradually accompanied by eerie string motifs and brass phrases. Recorded by vocalist Robert Aiki Aubrey Lowe, these wailing noises seem to point not just at the presence of the spacecraft (to which

2 Ironically, the inclusion of this song in the final soundtrack disqualified Jóhannsson's work for the 89th edition of the Academy Awards (2017) in the category of Best Original Score (Hall 2016). 
they are synced visually) but, most importantly, to its potential occupants: Are these alien creatures in pain? Are these sounds cries for help? Or is this just how they communicate? And ultimately, is this sound emanated by "them" at all? Concerning this last question, we see Jerrold Levinson's concept of "musical fictional personae theory" in action. Levinson argues that "since expressing requires an expresser, that means that in so hearing the music the listener is in effect committed to hearing an agent in the music" (Levinson 2007, 93). We tend to associate a source, an agent to music, and thereby add expression of emotion to the sounds. Therefore, this simple rule would account for the listener's default bias in hearing an agent into an otherwise unfamiliar sound. If such agency is established, considering the acousmatic ${ }^{3}$ nature of these voice-like utterances, that is, without seeing the source of the sound, it is easy to associate these sounds with whale song and all the possible meanings that come with it: signals deployed to map or explore new territories, to alarm for protection or to call for mating. ${ }^{4}$ The scene's acoustic riddle, together with its real-world connotations, seems to foreshadow to some extent the film's central theme of communication deciphering. ${ }^{5}$ At this point in the film, considering the scene's internal focalization through Banks's character, the narration's communicativeness is quite restricted, making any of these possible readings of the heard voices plausible. While they could be deemed as diegetic voices identified with the aliens, the mysterious sounds in combination with the rest of the music might also be understood as merely part of the film's experimental extra-diegetic soundtrack, setting the mood for our arrival to the camp. Once this establishing focalized/auricularized shot is concluded and we are on the ground with the passengers of the helicopter, the sonic space is rearranged once again: the music is sent to the background and the helicopter blades and other clearly diegetic sounds occupy the foreground.

Minutes later, when Banks and Donnelly are heading towards the spacecraft for the first time, a somewhat similar sonic atmosphere is created with Hydraulic

3 "Acousmatic, specifies an old dictionary, is said of a sound that is heard without its cause or source being seen. We can never praise Pierre Schaeffer enough for having unearthed this arcane word in the 1950s" (Chion 1999, 18).

4 Using whale song in science fiction films is not a rare occurrence. For example, it happens in David Carson's Star Trek: Generations (1994), about which Tom Kenny notes that, "The noise of the Klingon bird-of-prey spaceship contains the songs of whales, ironically enough. The mysterious Nexus energy wave, which appears at the climax of Generations combined more than 30 elements, including animal cries to give it a subliminal sense of a living, deadly creature” (Kenny 1995, 78).

$5 \quad$ When asked "Why do whales sing?" Alison Stimpert, bioacustician at Moss Landing Marine Laboratories in California, claimed that clear answers concerning their communicating system remain a mystery (Yandell 2017). 
Lift (Jóhannsson, at 00:24:10 in the film). Noteworthy here is another instance of internal auricularization with Adams's character, displacing the helicopter sounds to the background while foregrounding her breathing inside of the security suit she is wearing. As the scientists approach the spacecraft, voice-like wailing sounds, maybe even actual human voices, are heard. These, however, are processed in a way that ambiguates their human nature. The density of the sonic space increases as they enter the craft and access the gravity-shifting passage leading to the "meeting point."

In the second encounter with the aliens, one of the two heptapods raises one leg, and an ink-like black liquid emanates from it, separating first into three parts, to blend back together creating a circular logogram and by that presenting their written language for the first time. At this precise moment, a tellingly titled track Sapir-Whorf starts to play, introducing the first clearly recognizable human voices to the soundtrack: female voices start singing meaningless vocables, immediately forming an ethereal chorus (Jóhannsson, at 00:38:00 in the film). Repeatedly singing phrases of phonetic units, these vocal sounds refuse to convey a clear semantic meaning to the listener. They seem to parallel the experiencing of a foreign language or unknown code, especially since the catalyst of these sounds was the aliens' first act of (graphical) communication. Considering how we tend to repeat new words several times when we first learn/hear them (Banks herself is doing this: "Human... human..." while trying to communicate with the heptapods), the iterative nature of the voices in this segment might be seen to refer to, if not fully imitate, this strategy.

Later on, fearful about the heptapods' intentions, two members of the military team decide to set explosives inside the spacecraft. Aware of this, the heptapods reveal their entire "alphabet" to Banks, right before the explosives detonate. Featuring the track Properties of Explosive Materials (Jóhannsson, at 01:15:00 in the film), the scene is underscored by distorted and processed vocals playing in the background. The added layer of modulation to the already non-sensical voices, which could also be heard as instances of overtone singing practices, seems to further prevent the viewer from grasping meaning out of the vocalizations. Furthermore, considering the overwhelming amount of information the scientists have just been granted access to, these modulating vocals could reinforce the idea of trying to make sense out of the logograms (to achieve the correct modulation in order to understand the complex data).

After the detonations, the heptapods distance the spacecraft further from the ground, although remaining on site. China announces their ultimatum to the 
spaceship located on Chinese territory, providing the aliens with 24 hours to either leave or face destruction. The same group of female voices that played during the heptapods' first demonstration of graphical communication populates the soundtrack - Escalation (Jóhannsson, at 00:18:00 in the film) is adding a percussion layer to that, formed of mallets hitting on different types of wood. Soon after, a bigger orchestration joins the composition: strings, brass, percussions, and deep sustained male vocals culminate in a powerful build-up accompanying the growing tension in the story world.

While discussing the international crisis with the rest of the team, Banks's nonlinear time experience intensifies, something that regularly happens with her since the first contact, and so she decides to approach the spacecraft seeking an explanation. Once again we hear the utterances resembling whale song, seeming to play a somewhat inviting tune for Banks. As a capsule descends from the spaceship and lifts Banks up, the soundtrack incorporates anew the processed, modulating, overtone singing vocals that played during the aforementioned Properties of Explosive Materials.

There is one last - key - scene during which voices and voice-like sounds are featured in the soundtrack with a major role. This is when Banks finally manages to decipher the heptapod language. A flash-forward, in fact a chronological glimpse into the future (the gift Banks receives from the aliens), shows the linguist unpacking copies of her just published book The Universal Language, accompanied in the soundtrack by the introduction of the piano tape loops used throughout the film (Jóhannsson: Decyphering at 01:37:00 in the film). This is alternated with Banks and Donnelly's present time in the base camp (the film's deictic centre from which Banks's vision originates): looking at the recording of the entire alphabet the heptapods had shared with them previously. This crosscutting editing continues until we are focused on a close-up of Banks in a state of trance, when vocal sounds (the sort of modulating vocal sounds mentioned before) gradually gain presence in the sonic space, repeating the same sequence alternating two different pitches. On this occasion, as if Banks is hearing these, the voices seem to belong to the diegetic world, marking a decisive moment in the film - the moment of realization in which she all of a sudden understands the

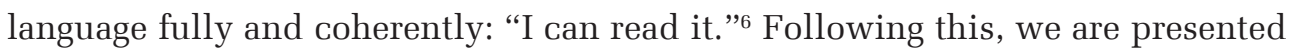
with other flash-forward-like glimpses of future lectures that she will be giving on

6 Banks's trance-like amazement is due to the realization of the effect of her supernatural ability that is her coming to understanding the paradox that she is able to read the alien language in the present because she has access to her own future and her then-published book on the translation of the logograms. 
the topic of the universal language, while the piano tape loops, the vocal sounds and a bass drum sequence play. All these conclude in Banks's full mastery of the aliens' gift: using the vision of her future encounter with Chinese General Shang (Tzi Ma) to change the present, that is to prevent the tense situation's military escalation (Jóhannsson: One of Twelve at 01:40:45 in the film). ${ }^{7}$

Finally, during the end credits, the track Kangaru (Jóhannsson, at 01:50:50 in the film) features, which is a percussion-removed variation on Heptapod $B$ (Jóhannsson, at 00:52:00 in the film) - the track that plays during a montage sequence halfway through the film, summarizing the knowledge scientists gathered about the aliens and their spaceship (we skipped it intentionally to examine it in more depth now). Since Kangaru accompanies only the end credits, we consider focusing on Heptapod B - that is, on the track's diegetically more prominent version - more fitting.

\subsection{Vocal Affordances in Heptapod B}

Heptapod $B$ is featured during the explanatory montage that follows the first two encounters with the aliens - when small breakthroughs helping the team understand their language are starting to be made. The previous scene ends with Banks starting to experience the consequences of understanding such a language, that is, experiencing time as non-linear. The language used by the heptapods moves in circles, without a defined beginning or end, which seems to mirror the way they view time - as a circular concept. Banks references the theory of Linguistic Relativity or Sapir-Whorf hypothesis, according to which the language you speak determines how you think, rewiring your brain and affecting your world view and cognition. Heptapod B is played almost in its entirety during this sequence.

A pattern of female voices opens the sequence and occupies the entire soundtrack for about 10 seconds, followed by Donnelly's explanatory voice-over, sending these vocal sounds slightly more to the aural background. The physicist starts wondering about the most obvious question: the nature of these creatures. His ultimate "Who are they?" proceeds to highlight a series of aspects that remain unknown to the team, among others, the advanced technology they display, the

7 During a meet and greet participation event of the film, screenwriter Eric Heisserer divulged Banks's mysterious message, presented in the film as a loose segment in Mandarin Chinese without subtitles, as a reminder of the passing words of the general's late wife - "In war there are no winners, only widows" -, which wisdom, received in his top-secret private phone number, resonated enough with Shang to withdraw his military forces (Patches 2016). 
reason behind their choice of those twelve landing areas, or the question of whether they communicate among these locations. The narration moves on to describe the specificities of the findings regarding the language: the key characteristic being that it is semasiographic (semasia: meaning + graphia: writing); i.e. it is a nonphonetic based language conveying meaning without sound.

According to the structure of the track's composition (see texture map-Figure 1), Heptapod B introduces different elements one by one: first tape loops creating the atmospheric background, then the voice-like sounds, the wood percussions, and the bass drum slowly transitioning from a minimalistic composition into a more saturated sonic space, finally woodwind instruments, strings and brass phrases reinforcing the strength of the song.

Let's take a closer look at some of the elements of this track separately:

Voice Pattern \#1: This is the first voice sequence that opens the track. In contrast to the third leaping voice entering later in the track, this voice pattern seems to establish more of a rhythmic configuration, which will later be reinforced and syncopated by the percussion elements: the wood percussion and the bass drum (synth). This voice seems hardly processed, at least in comparison with the other voices in this song, providing it with an organic characteristic. In light of general binaries such as female/male and natural/technological, it is especially remarkable that this first voice is the one articulating the organicism, which, as the song progresses, gets slowly subsumed in the mix, proving quite hard to be separated from the rest of the musical texture. This, conveying an enfolding of the organic into something that is likely to be heard as machinic, foregrounds the interplay of binaries. As for the contents of this voice pattern, it consists of monosyllabic articulations, in succession one after the other and varying in duration, resembling at times coding schemes such as the dits and dahs of Morse Code.

Voice Pattern \# 2: This second pattern seems to be adding layers of rhythmic complexity when it is combined with the first one. Similarly, the organic nature of this voice is reduced in comparison to the first voice pattern, that is, this voice track sounds more processed, less natural, moving along the organic-mechanic spectrum. Together they seem to create a somewhat unsettling sonic atmosphere, while, simultaneously, foreshadowing the percussion entering some seconds later in the soundtrack.

Leaping Voice: From the three voice-layers we can distinguish in the track, this one is most similar to utterances of a real (human) language. While the vocalizations do not seem to represent any clear intelligible words, at least in the languages we are familiar with, the higher pitch of these voices in comparison 
to the deep voices of the other two voice patterns could suggest a speaking voice (unknown as it may be). Still, at the same time, the voice sound seems to be processed, adding a slight robotic layer to the utterances. This voice starts featuring a sample by avant-garde singer Joan La Barbara (Erin - the fragment used in the Jóhannsson soundtrack starts at 3:10), creating two somewhat different sentences: (1) The first is repeated four times, the first two times the final syllable is left out, to be fully sang in the third and fourth iterations. (2) The same building process characterises the second phrase as well. Once this sequence of four repetitions is done, she goes back to the first phrase. Again, displaying the idea of building blocks of communication adds to the theme of constructing a language.

Choir: One minute into the song, a distant sounding choir of voices joins the track. Resembling the other voice patterns, these sing short articulated phrases, creating random melodic patterns that are later echoed by the strings. These voices seem to present a certain degree of processing, providing an ethereal aura to the entire piece.

Percussion: This element consists of mallets repeatedly hitting on what sound like different types of wooden materials. The rhythmic pattern these mallets create is not fixed, evolving and varying throughout the musical piece, both in its sound (because of the different drumming surfaces) and its speed. This percussion adds another layer of organicism to the mixture (together with the leaping voices, for example), further contributing to the rich interplay of processed and natural sounds. The organic feature of this percussion has a capacity to evoke primitive musical traditions, as far as their sonic naturalness is concerned.

Clearly, when analysed, the blend of actual image, film music and sound effects should be considered as a sort of textural unity, which, in turn, allows a series of possible connotations to emerge from this combination. As seen above, this track presents interplays between organic/mechanic voices as well as natural/processed sounds and utterances with varying degrees of recognizability as potential human language-ultimately emphasizing contrasts of human and non-human, subsumed and blended via rhythmic patterns. The ostinato and developing vocal utterances present in the track could be seen to emphasise a communicative dimension, while their varying degrees of organicism may broaden this dimension beyond the purely human context, as the voices approach greater levels of processing, therefore adopting a less human quality. Lastly, the reiterative hitting of mallets on wooden surfaces conforming the percussion layers, which seems more evocative of tribal rituals of spirituality and transcendental connection, further accentuates the binary nature of this soundtrack segment. 


\subsection{Overtone Singing Practice in the Soundtrack}

Let us consider another aspect of the same issue. As we have noted throughout the detailed analysis of different passages of the film, a variety of vocal practices and techniques are present in the soundtrack. These are: whale song, overtone singing, looping existing vocal recordings as well as different degrees in the processing of these voices. In what follows, we concentrate on the overtone singing practice, as it appears in the Properties of Explosive Materials or the Decyphering tracks. ${ }^{8}$

Piero Cosi and Graziano Tisato locate this singing tradition mostly in regions of Central Asia (Bashkortostan, Kazakhstan, Uzbekistan, Altai and Tuva, Khakassia and Mongolia) as well as South Africa (Xosa women), but they also mention Tibetan Buddhist chants and Rajastan (Cosi and Tisato 2003). They define overtone singing as "harmonic singing with an intentional emphasis on the harmonic melody of overtones. This is the name used by Western artists that utilizes vowels, mouth shaping, and upper-throat manipulations to produce melodies and textures" (2003). Although all musical sounds contain overtones, or tones that resonate in a certain relationship above a so-called fundamental tone, this singing practice seems to split the voice in two, causing the listener to experience the unusual sensation of a pure, discarnate, sine wave emanating from the sound (2003). Cosi and Tisato explain how, despite the different and unique manifestations of musical traditions in these diverse cultures, some of these singing practices seem to share one commonality: the production of overtones in their respective vocal music styles. Additionally, it is remarkable how, in spite of the different specificities of each of these traditions and their particular cultural contexts, they share another quality: permeating overtone singing with a layer of otherworldliness. Well-being, spirituality and health are typical associations made with overtone singing in Tibetan and Gregorian Chant, while Tuvan overtone singing carries meanings like shamanistic, aesthetic and animistic (2003). Furthermore, the authors state that Tuvans regard this sound as "the way preferred by the spirits of nature to reveal themselves and to communicate with the other living beings" (2003). The West gradually adopted the overtone singing tradition, with Karlheinz Stockhausen's 1968 Stimmung being credited as the first major Western musical composition based on a diphonic vocal technique. In a similar way to what happened in the regions where it originated, overtone

8 Due to their skillful experimentations in harmonic and overtone singing, Jóhannsson worked with the Danish vocal ensemble Theatre of Voices, conducted by Paul Hillier. Speaking of these vocalists, Jóhannsson stated, "they're very good at extended strange vocal techniques, like harmonic singing, coaxing these strange sounds out of the human voice” (Clark and Stanze 2016b). 
singing very soon turned as well to mystical, spiritual and even therapeutic applications (2003). Thus, it appears that there is a certain permeation into this vocal practice that seems to sparkle a kind of unearthly feeling in many listeners by revealing a somewhat hidden dimension of the voice. This has been ingrained, quite ironically as originally being "the bearer of a human personality" (Shepherd et al. 2003, 456), with varied associations to the unknown. All in all, such a strategy of triggering the concept of otherworldliness through exploring the potential affordances of overtone singing in the soundtrack of Arrival seems to be a subtle, but highly effective contributor to the film's central diegetic question about the human/alien divide.

Roland Barthes concluded his seminal essay, The Grain of the Voice on a corresponding note. He defined the grain as the perception of the (human) body in the voice as we hear the utterances and signing of such voice, tracing an analogy to the nexus that exists between hand and writing, or limb and performing. Simply put, according to Barthes, the voice is making us hear (thus bring into being) a body as the vocal sounds convey the materiality of the body speaking or singing (Barthes 1977, 188). There seems to be, thus, a clear connection between the perception of this grain in the voice and the human nature, the organicism we assign to the sounds. And this is something that is explored, as the above scanning of the soundtrack hopefully has shown, in several instances throughout the score of Arrival (especially in Heptapod B), where both natural - i.e. non-processed - and more machinic voices populate the sonic space of the film soundtrack, blending into one another or involving processes of subsumption.

The idea of exploiting the potential of such cognitively default anthropomorphization takes us to the work of Charity Marsh and Melissa West on binary oppositions in music. With regard to our case, their analysis of the music of Icelandic singer-songwriter Björk promises enlightening illustration. According to the authors' initial observation on sound, what is normally considered natural is defined in direct opposition to what is considered technological (Marsh and West 2003, 182). Acknowledging how certain artists blend or blur these binaries, they analyse in detail the different vocal characteristics occurring in Björk's 1997 album Homogenic. Marsh and West perceive Björk's primitive-sounding screams, emphasized by a sampled and digitized beat, as natural while at the same time being manipulated by something completely technological: underscoring the technological qualities added by the distortion of the beats and her voice, they also associate chantlike characteristics to the methodical rhythm of the voice and the beat $(2003,195)$. Listening to Heptapod $B$ while watching the montage 
sequence of Arrival, a certain parallel to this phenomenon of opposition is discernible. On the one hand, the different voices present different degrees of processing, with the one previously named Voice pattern \#1 exhibiting an organicism later reduced with the second pattern, and then again contrasted with the main female Leaping voice (the fragment spliced from La Barbara's original performance). On the other hand, however, it is not just the interplay of the organic and non-organic nature of the voices that partake in this binary interaction. For one, there is an atmospheric drone in the piece, which is also present throughout most of the film soundtrack (created with a 16-track analog tape loop, adding successively piano notes, without the attack of the note but just the tail of the sound, layered on top of each other, at different speeds). This background sound, consisting mainly of piano and magnetic tape, is almost nonprocessed, with the exception of some reverb (Clark and Stanze 2016b). Further, a very raw percussion, featuring different types of wood hit by mallets joins the sound combination, now with the percussion adding another layer of the natural to the piece, and therefore contrasting with the highly technological display of the film images during this sequence and the processed sounds of the music such as some of the voice patterns or the bass synth. In this way, the binary interplay between the different vocal layers of the soundtrack (subsumed by the rest of the musical layers) seems to complement the broader thematic concern of the film, that of the human/non-human explorations.

\section{Avant-garde Influence}

Finally, zooming out of our close reading, we would like to take a look at how Jóhannsson's work on Arrival embeds itself in a long-existing tradition of collaborations between musical avant-garde and the world of film music, as such a contextualization might contribute to our present aim of mapping the representational strategies of the alien/human divide.

The intention to experiment with novel forms of musical expressivity, novel in the realm of mainstream cinema, seems to be something Jóhannsson had in mind already from the early stages of his work on the film: "there were more things to avoid rather than things to use! There are some things that are clichéd or overused, elements that one associates with science fiction that I wanted to avoid" (Hall 2016). This is in line with what Lisa M. Schmidt warns about, seeing similar dangers when stating that the history of scoring within the genre of science fiction continues to be an exploration of certain conventions and tropes (Schmidt 2010, 
34). Intriguing then, in this respect, is the manner in which unfamiliar sounds eventually find their place in science fiction soundtracks. For example, Schmidt explains how, in relation to electronic music, the lack of minute alterations in electronic sounds, regardless of how pleasing to the ear, will always signify a certain anxiety about authenticity, predestined to be alien (2010, 36). Positioning the alien as something beyond the boundaries of the norm(al), much like the avant-garde itself $(2010,38)$, she then identifies a common ground between avantgarde music and sci-fi films in their shared pursuit of representing the alien.

In the case of Arrival, Jóhannsson embraced a series of techniques and practices informed by avant-garde traditions. For example, the tape loop, employed to create the background drones that set the tone of the film, is an old technique that has been used by composers like Karlheinz Stockhausen, Pierre Schaeffer or Brian Eno. As Jóhannsson explains, "we were doing sound-on-sound recording, recording over the sound while keeping the previous sound so we had this [sic!] ghostly remains of the previous loop" (Hirway 2016). The decision to compose a musical background using this looping technique directly refers to the film's core idea of diegetic non-linearity and endless time recurrence. In line with this view, the resulting drone seems to repeat incessantly, featuring no sharp beginning or ending sounds, an effect achieved by including only the sustain and decay of the overlapping piano notes.

Jóhannsson also names Gérard Grisey and Horațiu Rădulescu - seminal figures associated to the musical practices of spatialization and spectral music - as sources of inspiration for the score (O'Connell 2016). In particular, the saturation of the spectral space is notable throughout the film score, adding layers of sounds occupying different regions of the spectral space, usually building up from the lower ranges. With reference to spectrality, Lelio Camilleri explains how "the combination of the spectral content of sounds and their disposition can accentuate the various sensory experiences" $(2010,202)$. The sounds comprising the film music tracks seem to fill up the film's sonic spaces, distributed both in terms of localized space and spectral space. Regarding the former, the different sonic elements (voices, strings, brass, drums, etc.) present variety in terms of their foreground/background placement in the sonic space as well as their motion within it (foreground to background, left to right and vice versa). In combination to this, the audience can perceive "the sense of saturation or emptiness due to the spectral content of the sounds used" (Camilleri 2010, 202), that is, the timbre of the different sounds which characterizes the compositions. This approach has been purposely employed by Jóhannsson throughout his previous collaborations with Villeneuve: 
in Prisoners (e.g. The Keeper, 2013) and Sicario (e.g. The Beast, 2015), similarly to Arrival. Figures 2-4 show three screenshots taken from an online spectrograph tool we fed with Jóhannsson's Heptapod B, demonstrating the progression in saturation of the spectral space in the track. ${ }^{9}$ Looking at the spectrograph at three consecutive moments in time, one can appreciate how the spectral space is slowly saturated as the piece progresses, potentially contributing, as Camilleri argues, to the heightening of the sensory experiences afforded by the film.

In resorting to techniques such as these, Jóhannsson's score for Arrival partakes in the dialogue of avant-garde music tradition informing mainstream film music making, commonly employed in cases of sci-fi's explorations of the unknown, like the one Arrival is concerned with.

Mentioned by Jóhannsson (Baines 2016) as an influence on his work, vocalist Meredith Monk argues that the voice is a kind of language that somehow crosses cultural and linguistic barriers, "speaking directly to people on an intuitive level" (Lentjes 2017). This is the dimension explored by the soundtrack we have focused on herein, that is, the intrinsic power of the voice to represent humanity, and, at the same time, the potential offered by its experimentation for charting unknown territories. Jóhannsson's utilization of a wide range of vocal experimentations is a thoughtful approach to capitalize on such a power of the voice and to justify its use within a film which deals with this very subject matter. While this is not remarkably new in the world of music in general, it represents an innovative practice leaking into mainstream cinema.

\section{References}

Altman, Rick, McGraw Jones, and Sonia Tatroe. 2000. Inventing the Cinema Soundtrack: Hollywood's Multiplane Sound System. In Music and Cinema, eds. James Buhler, Caryl Flinn, and David Neumeyer, 339-359. Hanover: Wesleyan University Press.

Baines, Josh. 2016. We Got Jóhann Jóhannsson to Conjure Up a Mythical and Futuristic Playlist. Vice. https://www.vice.com/en_uk/article/jp9xy7/jhannjhannsson-mythical-futuristic-playlist. Last accessed 20. 03. 2021. Barthes, Roland. 1977. Image, Music and Text. London: Fontana Press.

9 The online spectrograph tool is a project of Edward Ball at Academo (UK) and Prof. Michael J. Ruiz at UNC Asheville (USA), based on work by Boris Smus of Google (USA). https://academo. org/articles/spectrogram/. Last accessed 20. 03. 2021. 
Brend, Mark. 2012. The Sound of Tomorrow: How Electronic Music Was Smuggled into the Mainstream. New York and London: Bloomsbury Academic.

Camilleri, Lelio. 2010. Shaping Sounds, Shaping Spaces. Popular Music vol. 29, no. 2 (May): 199-211.

Chiang, Ted. 2005. Stories of Your Life and Others. New York: Pan MacMillan.

Chion, Michel. 1999. The Voice in Cinema. New York: Columbia University Press.

Clark, K. and Stanze, E. (2016a). Acoustic Signatures: The Sound Design. Behind the scenes featurette of Arrival [Blu-ray Disc], Paramount Pictures.

Clark, K. and Stanze, E. (2016b). Eternal Recurrence: The Score. Behind the scenes featurette of Arrival [Blu-ray Disc], Paramount Pictures.

Cosi, Piero and Graziano Tisato. 2003. On the Magic of Overtone Singing. In Voce, Canto, Parlato. Studi di Onore di Franco Ferrero [Voice, Song, Speech. Studies in the Honour of Franco Ferrero], eds. Piero Cosi, Emanuela Magno Caldognetto, and Antonio Zamboni, 83-100. Padova: Unipress.

Deleon, Cara M. 2010. A Familiar Sound in a New Place: The Use of the Musical Score Within the Science Fiction Film. In Sounds of the Future, ed. Mathew J. Bartkowiak, 10-21. Jefferson, North Carolina, and London: McFarland.

Hall, Jacob. 2016. Interview: Arrival Composer Jóhann Jóhannsson on How You Score First Contact. Slashfilm. https://www.slashfilm.com/johann-johannssonarrival-music/. Last accessed 20. 03. 2020. Hirway, Hrishikesh. 2016. Song Exploder: Jóhann Jóhannsson on the Secrets of Arrival's Score. Vulture. https:// www.vulture.com/2016/11/arrival-score-johann-johannsson-song-exploder. html. Last accessed 20. 03. 2021.

Kenny, Tom. 1995. Star Trek Generations. Mix: Professional Recording, Sound and Music Production vol. 19, no. 1 (January): 72-83.

Lentjes, Rebecca. 2017. The Essence of Voices. VAN Magazine. https://van-us. atavist.com/against-the-grain. Last accessed 20. 03. 2021.

Levinson, Jerrold. 2007. Contemplating Art: Essays in Aesthetics. Oxford and New York: Oxford University Press.

Marsh, Charity and Melissa West. 2003. The Nature/Technology Binary Opposition Dismantled in the Music of Madonna and Björk. In Music and Technoculture, eds. René T. A. Lysloff and Leslie C. Gay, 182-203. Middletown: Wesleyan University Press.

O’Connell, Sharon. 2016. Arrival composer Jóhann Jóhannsson: People are hungry for new sounds. The Guardian. https://www.theguardian.com/ music/2016/nov/26/arrival-johann-johannsson-soundtrack-oscar-nominated. Last accessed 20. 03. 2021. 
Patches, Matt. 2016. The Mystery Line in Arrival Revealed. Thrillist. https://www. thrillist.com/entertainment/nation/arrival-chinese-line-ending. Last accessed 20. 03. 2021.

Schmidt, Lisa M. 2010. A Popular Avant-Garde: The Paradoxical Tradition of Electronic and Atonal Sounds in Sci-Fi Music Scoring. In Sounds of the Future, ed. Mathew J. Bartkowiak, 22-41. Jefferson, North Carolina, and London: McFarland.

Shepherd, John, David Horn, Dave Laing, Paul Oliver, and Peter Wicke. 2003. Continuum Encyclopedia of Popular Music of the World, Volume II: Performance and Production. London and New York: Continuum.

Yandell, Kate. 2017. The Mystery of Whale Song. The Scientist. https://www.thescientist.com/features/the-mystery-of-whale-song-31945. Last accessed 20. 03. 2021.

\section{List of Figures}

Figure 1: Texture map of the track Heptapod B.

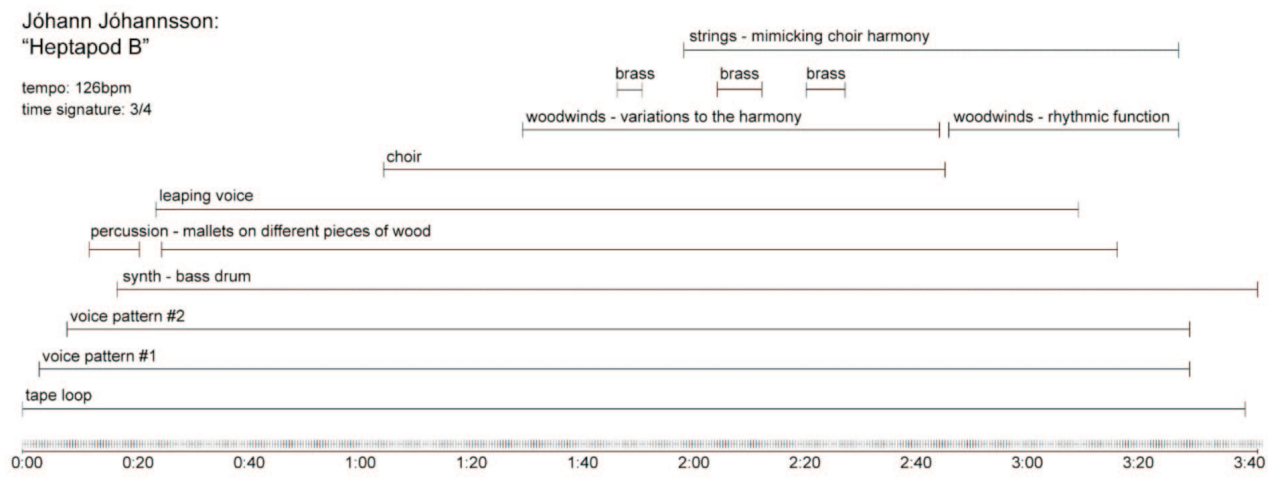


Figure 2: Spectrograph-screenshot of Heptapod B at 00:07, low saturation of spectral space.

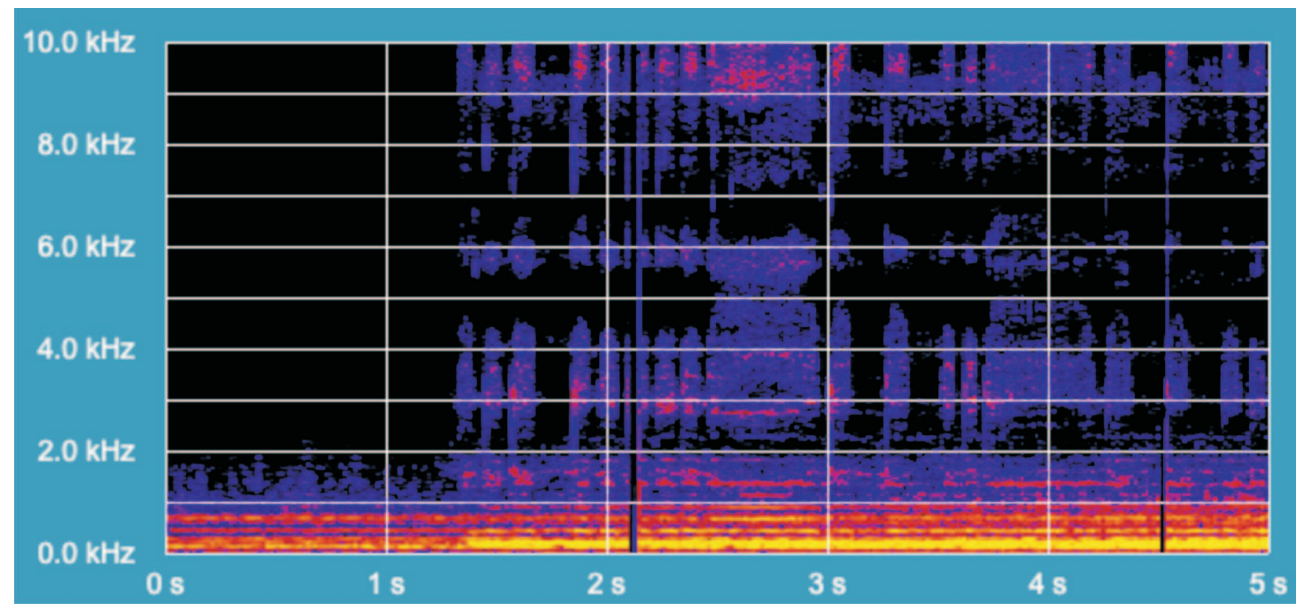

Figure 3: Spectrograph-screenshot of Heptapod B at 00:55, medium saturation of spectral space.

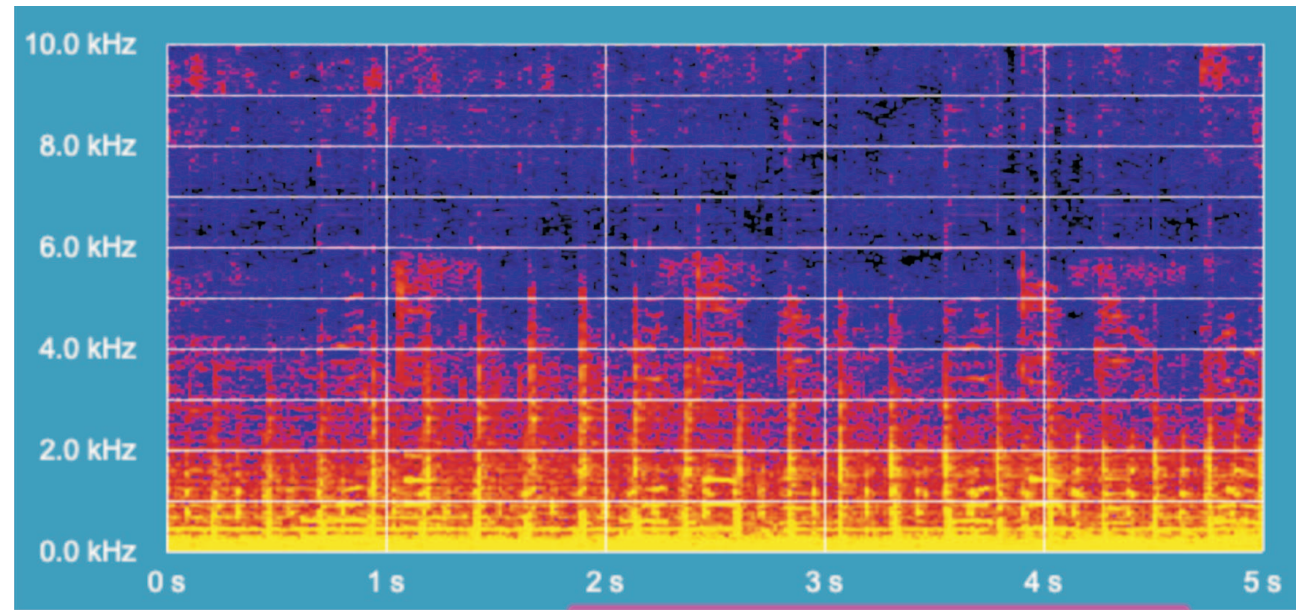


Figure 4: Spectrograph-screenshot of Heptapod $B$ at 02:12, high saturation of spectral space.

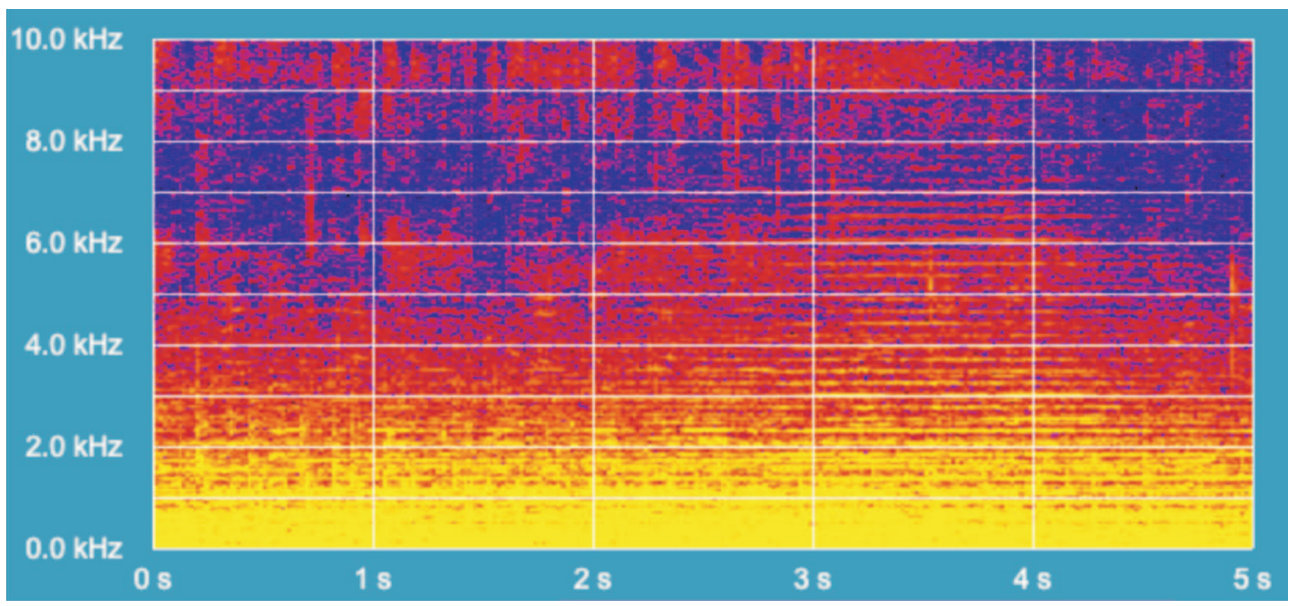

